\title{
Evaluation of a smoking cessation intervention for Dutch employees consisting of self help methods and a group programme
}

\author{
Marc C Willemsen, Hein de Vries
}

\begin{abstract}
Objective - To report the first evaluation of a worksite smoking cessation intervention in The Netherlands.

Design and setting - A quasi-experimental design was used to study the programme impact. The programme was implemented in one site of a large Dutch telecommunications company, and compared with a no-intervention control site of the same company.
\end{abstract}

Subjects-Smoking employees who wanted to quit smoking.

Intervention-Questionnaire assessing quitting motivation and barriers to quit, and the level of nicotine dependence; tailored letter of advice; offer of a self help guide, a group cessation programme, and a telephone quit line.

Main outcome measures - Point prevalence smoking status at three and 12 months post-intervention, daily smoking rate, and observed movement in stage of change.

Results - There were significant differences on all outcome measures at three month follow up between the conditions, but these differences were not sustained at 12 months.

Conclusion-In The Netherlands, comprehensive multicomponent programmes may be needed to achieve a sustained impact on worksite smoking prevalence.

(Tobacco Control 1995; 4: 351-354)

Keywords: worksite smoking cessation; stages of change; self help programmes

The mortality attributed to smoking has been estimated at 29900 for 1995 in The Netherlands. ${ }^{1}$ The prevalence of daily smoking in The Netherlands appears to have stabilised at approximately $34 \%$ of the adult population, after a steady decline from the 1950 s to the beginning of the 1990s. ${ }^{2}$ Smokers move through a series of motivational stages in their efforts to quit. ${ }^{3-5}$ A telephone survey of 931 randomly selected smokers in a national survey showed that at the end of $1990,70 \%$ of Dutch smokers were precontemplators (that is, reporting no intention to quit within the next six months), $23 \%$ were contemplating quitting within the next six months, and only $7 \%$ were in the preparation stage (planning to quit within the next 30 days). ${ }^{6}$ Smoking cessation efforts therefore remain a high priority in The Netherlands. One of the intervention challenges is to stimulate contemplators and those in the preparation stage to make a successful quit attempt. The worksite is one setting in which smokers can be reached.

The impact of a smoking cessation method can best be conceptualised as the recruitment rate multiplied by the quit rate. ${ }^{7}$ With a self help approach, company-wide participation of smoking employees would be relatively high, but the quit rate would be relatively low, in the range of $5-15 \%{ }^{8}$ With a group programme, participation would be much lower, but success rates would be higher, in the range of 20-30\%. ${ }^{9}$ Presenting programmes in a manner consistent with smokers' preferences may improve programme efficacy. Allowing smokers to choose the type of intervention may contribute to a programme's attractiveness and therefore to the participation rate. ${ }^{10}$ However, this assumption has not yet been examined extensively. ${ }^{11}$ Our intervention allowed smoking employees to choose a group programme or a self help method (or both). It was expected that both methods would contribute equally to the impact of the intervention.

We report results of the first known smoking cessation programme in Dutch worksites. This programme was developed as part of a larger cancer prevention research programme. ${ }^{12} \mathrm{Par}-$ ticipant ratings of the various programme components are also presented.

\section{Methods}

\section{RECRUITMENT PROCEDURE}

A quasi-experimental design was used to study the impact of a worksite quit smoking programme in a large Dutch telecommunications company. Two districts of the company were involved in the study. The experimental district consisted of 1735 employees, the control district of 2800 employees. Each district included one headquarters, five to eight large sites, and several small sites. The company indicated that both districts had the same very liberal smoking policy with hardly any restrictions. Both districts had the same percentage of male employees. Univariate comparisons showed that the control district had more employees in the age category of 25-35 years, and fewer aged $45-55$ years. In each district, 
smokers were recruited by an announcement in the district's bulletin and an introduction letter with an entry form. They could select a self help guide, a group programme, or both. Participation in the programme was voluntary and free of charge.

In the experimental district, 155 smokers enrolled in the programme. Fifty two applicants $(33 \%)$ requested the group programme, $92(59 \%)$ preferred self help, and $11(8 \%)$ did not indicate a preference. Of those who stated their interest in the group programme, 23 actually joined one of two group courses. The others received a self help manual by default. The 11 smokers who did not indicate a preference for a specific quit mode received a self help manual. All 155 applicants were invited to call the project's telephone quit line.

In the control district, 239 smokers enrolled, of whom $38 \%$ preferred the group programme, $57 \%$ preferred the self help manual, and $5 \%$ reported no preference. Applicants were informed that the company was considering future action, but that no immediate activities were planned, creating a "waiting list" control group.

\section{INTERVENTION}

All smokers in the experimental condition were offered the following programme components.

\section{Self help method: manual and tailored letters}

The Dutch self help guide is partly based on the self help manual from the American Lung Association's "Freedom From Smoking" guide. ${ }^{13}$ The guide was pretested and evaluated in other projects. ${ }^{14} \mathrm{~A}$ short questionnaire assessing quitting motivation and barriers, and level of nicotine dependence, was included in the entry form. Results were used to tailor a letter to the individual's concerns. Tailored letters were generated with help of computer algorithms and laser printed by the research team. About 150 combinations of advice were possible. Advice was tailored to motivational level (high or low), expected barriers to quit (for example, gaining weight, stress, withdrawal symptoms, social pressure, and problems in maintaining abstinence), and nicotine dependence (those who smoked more than 16 cigarettes per day were advised to consider using nicotine replacement therapy). The objective of the tailored letter was to help make the information in the manual more personally relevant.

\section{Group programme}

The group programme was the standard smoking cessation programme offered by the Dutch Foundation of Smoking and Health. The courses were conducted outside working time, but within company facilities. One course was led by an experienced counsellor from outside the company, the other by an in-house educator who received special instruction and training for this task. Participation costs (equi- valent to US\$50) were paid for by the company. The group programme consisted of eight 90 minute meetings, spread over three weeks. In the first session, participants were prepared for quitting in the second meeting. The following sessions emphasised the participants' own potential to fight addiction, and focused on preparing for nicotine withdrawal symptoms and relapse prevention by exchanging experiences and discussing the difficulties and risk situations encountered by the participants. Suggestions on how to cope with these difficulties were presented - such as the use of rewards and nicotine replacement methods and relaxation techniques were practised.

Quit line

During working hours, smokers could call a telephone quit line, which was operated by the worksite physician or nurse.

\section{QUESTIONNAIRE AND OUTCOME MEASURES}

The baseline questionnaire assessed smoking behaviour, number of previous quit attempts, and sociodemographics (age, sex, education). Various three month and 12 month follow up measures were used to evaluate programme effectiveness, including movement through the stages of change, ${ }^{15}$ daily cigarette consumption, and point prevalence abstinence (for example, "Have you smoked in the past seven days, even if just one puff?"). Self reports were used because biochemical validation was not possible due to restraints by the company management. At the three month follow up, the questionnaire also assessed the participants' awareness of, use of, and evaluation of the different programme components.

\section{SUBJECTS AND DATA COLLECTION}

All data were collected through telephone interviews conducted by trained students. Baseline data were collected from 127 of 155 applicants in the experimental district $(82 \%$ response rate) and from 187 of 239 applicants in the control condition ( $78 \%$ response rate). Follow up surveys were conducted at three and 12 months after the programme. Response rates at three month follow up were $90 \%$ for the experimental condition and $82 \%$ for the control group. At the one year follow up, response rates were $85 \%$ in the experimental condition and $62 \%$ in the control group. Attrition between pre-test and the first posttest was mainly due to incorrect telephone numbers. At the second follow up, the main reason was refusal to take part in the survey.

At the 12 month follow up 35 control subjects indicated having read the self help manual. Because these subjects did not differ significantly from the other control subjects on any of the demographic or smoking history variables (including stage of change), they were excluded from the analyses of 12 month results. Exclusion of these control subjects did not affect the comparability of the experimental to the control group. 


\section{Results}

At baseline, the control group was younger than the experimental group (37 $v 40$ years; $\mathrm{F}(1,277)=6.05 ; \mathrm{p} \leqslant 0.05)$, reflecting a difference in age distribution between the control and experimental districts. No significant differences were found with respect to cigarette consumption, number of previous quit attempts, gender, educational level, and stage of change, in either the pre-test or the first post-test. On average, the respondents in both conditions smoked 18 cigarettes per day and had made two previous quit attempts. By comparison, the Dutch smoking population in 1990 smoked 16.6 cigarettes per day and had had an average of 2.7 previous quit attempts. ${ }^{16}$ There were more males $(80 \%)$ in our sample of smokers than in the overall Dutch smoking population $(69 \%) .{ }^{16}$ Fifty seven percent of the smokers in our sample smoked only hand rolled cigarettes (shag), $27 \%$ smoked only factory made cigarettes, while the remainder smoked a combination of tobacco products (hand rolled, factory made, or pipes and cigars). At baseline, $18 \%$ were in the precontemplation stage, $60 \%$ were in the contemplation stage, and $22 \%$ were in the preparation stage.

\section{PROGRAMME EVALUATION}

The self help manual was read by $90 \%$ of the respondents, and $18 \%$ had participated in a group course. The majority $(64 \%)$ could not recall having read the tailored letter. Process analysis showed that smokers confused the tailored letter with a formal introduction letter that went with the package. Fifty percent of the respondents knew of the existence of the telephone quit line, but only $2 \%$ actually used it. Participants were asked to rate the self help manual, the group programme, the tailored letter, and the quit line on an evaluation scale from 1 (bad) to 10 (excellent). All programme components were given an average score higher than 7 , indicating an overall positive evaluation.

\section{BEHAVIOURAL OUTCOMES}

Following established guidelines, all individuals who could not be contacted at follow up were counted as smokers. ${ }^{17}$ The initial quit rate at the end of the group programme was $43 \%(10 / 23)$ and the seven day point prevalence quit rates were $26 \%(6 / 23)$ at three months and $22 \%(5 / 23)$ at 12 months. Quit rates for the self help participants were $8 \%$ $(8 / 104)$ at three months and $7 \%(7 / 104)$ at the one year follow up.

To compare the intervention district with the control district, the group programme participants and the self help participants were pooled. Overall, in the experimental district the seven day point prevalence quit rate at three months was $11 \%(14 / 127)$ compared with $2 \%$ in the control group (3/152); the difference was significant $\left(\chi^{2}(1)=11.33 ; p<\right.$ 0.001 , using Yates correction). At the one year follow up, in the experimental condition the quit rate had decreased to $9 \%(12 / 127)$, whereas it had increased in the control condition to $8 \%(12 / 152)$; the difference between conditions was no longer significant.

In both conditions the smokers who did not quit reduced their daily consumption from baseline to the three month follow up. This reduction was greater in the experimental condition (from 18.2 to 14.2 cigarettes) than in the control condition (from 19.0 to 17.8 cigarettes; $F(1,239)=16.81 ; \mathrm{p}<0.001)$. This difference disappeared at the one year follow up.

\section{STAGES OF CHANGE MOVEMENT}

By the three month follow up, $36 \%$ of respondents in the intervention condition advanced at least one step through the stages of change, $34 \%$ stayed in the same stage, and $30 \%$ fell back one or more stages. The controls progressed in $17 \%$ of the cases, $62 \%$ remained stable, and $21 \%$ fell back one or more stages. The changes were significantly more often positive in the experimental group compared with the control group $\left(\chi^{2}=20.21 ; \mathrm{df}=2\right.$; $\mathrm{p}<0.001$ ). From baseline to one year follow up, $26 \%$ of the respondents in the intervention condition had advanced at least one step through the stages of change, $37 \%$ stayed in the same stage, and $37 \%$ fell back one or more stages. These percentages did not differ significantly from those observed in the control group using the $\chi^{2}$ test.

In the intervention group at three month follow up, $26 \%$ of precontemplators (5/19), $50 \%$ of contemplators $(33 / 66)$, and $75 \%$ of those in the preparation stage $(18 / 24)$ had attempted to quit, whereas $5 \%$ of precontemplators, $14 \%$ of contemplators, and $17 \%$ of those in the preparation stage had successfully stopped smoking.

\section{Discussion}

This paper reports on the first study conducted in The Netherlands to evaluate the effectiveness of a worksite smoking cessation programme. The intervention had a significant impact on smoking cessation at three month follow up. Twice as many intervention subjects improved in stage compared with the controls ( $36 \%$ versus $17 \%$ ). This coincided with the observed improvements in the two other smoking cessation outcomes: three month point prevalence abstinence and daily cigarette consumption among continuing smokers.

Prochaska and colleagues reported cross sectional data suggesting that an increase of one stage of change doubles the percentage of smokers taking action..$^{18}$ Our results show that contemplators have indeed twice the chance of making an attempt to quit compared with precontemplators. However, the increase from contemplation to preparation was accompanied by an increase from $50 \%$ to $75 \%$, less than double. Still, observed movement through the stages of change can be a useful method of detecting initial programme impact, which cannot be detected by only measuring smoking 
status. It should be noted that stage of change is a self reported measure and is sensitive to demand characteristics, especially with respondents who had already stated their interest in participating in a smoking cessation programme. These smokers might be reluctant to acknowledge that they have no intention of stopping smoking in the near future.

The addition of a telephone quit line to the intervention was not very successful. Very few smokers made use of the quit line, and only $50 \%$ recalled its existence. One reason might be that the line was only available during working hours, often the time when it is easiest for employees to refrain from smoking. The low awareness level and poor utilisation of the tailored letters suggest that this method was not optimally implemented. As a result, the programme impact at the three month follow up should thus be attributed mainly to the self help manuals and the group courses.

The finding that there were no sustained differences between the intervention group and the control group after three months points to the need for continuation of the intervention. ${ }^{19}$

Our study has some methodological and logistic limitations. First, the unit of analysis (subjects) was different from the unit of assignment (worksites). Efforts were undertaken to include more districts of the company in the study, but this was not feasible because the company management was not convinced of the need to include more districts in this pilot study. We would recommend replication of the findings from our study by a study involving more worksites.

Secondly, the observed increase in point prevalence quit rate in the control group between the first and second follow up measurements makes the interpretation of the long term effects of the programme difficult. This increase in the control group might have resulted from the waiting list status of the control subjects, causing them to delay stopping smoking until after the first post-test. Furthermore, it is possible that waiting list control subjects especially were triggered to stop smoking by a national antismoking campaign involving frequent media coverage conducted in The Netherlands during December 1990 (soon after the three month follow up).

Another limitation of the study is that it relied on self reported smoking status. However, misreporting rates are usually very low, except in situations that explicitly elicit socially desirable reports of smoking status, such as when outcomes are connected to incentives (which was not the case in our study). ${ }^{15}$ The subjects in this study were interviewed under conditions of strict confidentiality to reduce the chance of misreporting.

The results of this intervention can be used as an impact bench mark for more intensive multicomponent programmes such as proposed by Abrams et al, targeted not only at the individual, but also at the social environment and the organisation as a whole.$^{20}$ Such a broad programme could include restrictive no smoking policies and an educational and publicity campaign to motivate precontemplators to participate in the programme and to consider quitting.

The authors thank Victor J. Srecher for his advice on intervention development and Wayne Velicer for his comments on an earlier draft of this article. This study was made possible by grants from the Dutch Cancer Society and PTT Telecom.

1 Peto R, Lopez AD, Boreham J, Thun M, Heath C. Mortality from tobacco in developed countries: indirect estimation from national vital statistics. Lancet 1992; 339: 1267-8.

2 Smoking and Health Foundation [Stichting Volksgezondheid en Roken]. Annual report 1992 [Jaarverslag 1992]. Den Haag: Stichting Volksgezondheid en Roken, 1992].

3 Prochaska JO, DiClemente CC. Stages and processes of self-change of smoking: toward an integrative model of change. F Consult Clin Psychol 1983; 51: 390-5.

4 Prochaska JO, DiClemente CC. Stages of change in the modification of problem behaviors. Prog Behav Modification 1991; 28: 184-218.

5 Prochaska JO, Velicer WR, DiClemente CC, Fava J. Measuring processes of change: applications to the cessation of smoking. $\mathcal{F}$ Consult Clin Psychol 1988; 56:
$520-8$.

6 Mudde A, Dolders $M$, DeVries $H$. Evaluation of the intervention: the adult population. In: Baan B, Breteler HMH, Van der Rijt GAJ, eds. Evaluation of the intervention 'Let's stop smoking together'. Den Haag: intervention 'Let's stop smoking together'. Den Haag:

7 Velicer WF, Rossi JS, Ruggiero L, Prochaska JO. Minimal interventions appropriate for an entire population of smokers. In: Richmond R, ed. Interventions for smokers an international perspective. Baltimore: Williams \& Wilkins, 1994: 69-92.

8 Davis AL, Faust R, Ordentlich M. Self-help smoking cessation and maintenance programs: a comparative study with 12-month follow-up by the America Lung Association. Am f Public Health 1984; 4: 1212-7.

9 Klesges RC, Cigrang J, Glasgow RE. Worksite smoking modification programs: a state-of-the-art review and directions for future research. Current Psychol Res Rev $1987 ; 6: 26-56$.

10 US Department of Health and Human Services. The health consequences of smoking: Cancer and chronic lung disease in the workplace. A report of the Surgeon General, 1985. the workplace. A report of the Surgeon General, 1985. Rockville, Maryland: Public Health Service, Office on (CDC) 85-50207.)

11 Spoth R. Smoking cessation program preferences associated with stage of quitting. Addict Behav 1991; 16: 427-40.

12 De Vries H. Prevention of cancer: towards a national ABC Framework. Eur J Cancer Clin Oncol 1989; 25: 1025-33.

13 Strecher VJ, Rimer BK, Monaco KD. Development of new self-help guide - Freedom from smoking for you and your family. Health Educ $Q$ 1984; 16: 101-12.

14 Mudde AN, De Vries H, Willemsen MC, van Assema P. In: Richmond R, ed. Interventions for smokers: an international perspective. Baltimore: Williams \& Wilkins 1994: 293-322.

15 Velicer WF, Prochaska JO, Rossi JS, Snow MG. Assessing outcome in smoking cessation studies. Psychol Bull 1992 . 111: $23-41$.

16 Mudde AN. The development and evaluation of a community and a mass media approach to smoking cessation. Maastricht: University of Limburg, PhD thesis.

17 Lando HA. Treatment outcome evaluation methodology in smoking cessation: strengths and key issues. Adv Behav Res Ther 1989; 11: 201-14.

18 Prochaska JO, DiClemente CC, Norcross JC. In search of how people change: applications to addictive behaviors. Am Psychol 1992; 47: 1102-14.

19 Lichtenstein E, Glasgow RE. Smoking cessation: what have we learned over the past decade? $\mathcal{F}$ Consult Clin Psychol 1992; 60: 518-27.

20 Abrams DB, Emmon KM, Linnan L, Biener L. Smoking cessation at the workplace: conceptual and practical considerations. In: Richmond R, ed. Interventions for smokers : an international perspective. Baltimore: Williams \& Wilkins, 1994: 137-69. 